\title{
Accuracy of waist circumference for predicting other components of metabolic syndrome: evidence from the Bambuí cohort study of the elderly
}

Keila Bacelar Duarte de Morais'

Cibele Comini César ${ }^{2,3}$

Sérgio Viana Peixoto $0^{3,4}$

Maria Fernanda Lima-Costa,

\section{Abstract}

Objectives: To examine the accuracy of waist circumference to predict two or more metabolic syndrome (MS) components among the elderly and to compare it with the recommendations of the Joint Interim Statement (JIS) for adults. Method: The study was conducted among participants of the baseline of the Bambuí (Minas Gerais) Cohort Study. The best waist circumference cut-off point for the outcome was determined by the Younden Index. The accuracy of such cut-off points was assessed by the area under the ROC curve (AUROC) and the sensitivity, specificity and positive and negative predictive values. Results: The prevalence of MS was $63.8 \%$ among women and $43.4 \%$ among men. Of these, the waist circumference cut-off that best predicted two or more components of MS $(\geq 88 \mathrm{~cm})$ was similar to that recommended by JIS $(\geq 90 \mathrm{~cm})($ AUROC $=0.673$ and 0.672 , respectively). Among women, the corresponding value was higher $(\geq 92 \mathrm{~cm})$ than recommended by the JIS ( $\geq 80 \mathrm{~cm}$ ) (AUROC $=0.605$ and 0.560 , respectively). Conclusion: The overall accuracy of waist circumference (AUROC) for the outcome was low for both genders, indicating that this measure is not an effective predictor of other components of MS in the study population.

\footnotetext{
Fundação Oswaldo Cruz, Instituto René Rachou, Programa de Pós-graduação em Saúde Coletiva. Belo Horizonte, Minas Gerais, Brasil.

2 Universidade Federal de Minas Gerais, Faculdade de Ciências Econômicas, Centro de Desenvolvimento e Planejamento Regional. Belo Horizonte, Minas Gerais, Brasil.

3 Fundação Oswaldo Cruz, Instituto René Rachou, Núcleo de Estudos em Saúde Pública e Envelhecimento. Belo Horizonte, Minas Gerais, Brasil.

4 Universidade Federal de Minas Gerais, Escola de Enfermagem, Departamento de Enfermagem Aplicada. Belo Horizonte, Minas Gerais, Brasil.
}

\section{Keywords: Waist}

Circumference. Health of the Elderly. Metabolic Syndrome. Accuracy. 


\section{INTRODUCTION}

Metabolic Syndrome (MS) is a complex disorder represented by a set of factors related to central fat deposition and insulin resistance. The progressive increase in the occurrence of diabetes and cardiovascular events with advancing age makes MS particularly relevant among older age groups ${ }^{1,2}$.

There are different diagnostic criteria for MS. More recently, a Joint Interim Statement (JIS) ${ }^{3}$ was issued, which adopted cutoff points for the circumference of more sensitive waists, which is not essential for the diagnosis of the syndrome. While these criteria are recommended for the adult population, there is no specific recommendation for the elderly population.

As it is an easily obtainable measure, waist circumference can be used for tracking other factors that make up MS, the assessment of which depends on biochemical and blood pressure measurements. However, to our knowledge, few studies have examined the accuracy of waist circumference in the prediction of other factors that comprise MS among the elderly $y^{4-7}$. Considering the different values found in these studies, new investigations among different populations are required to determine cutoff points that may be useful in predicting the other components of MS among elderly individuals.

The present study aimed to determine the waist circumference cut-off points for the prediction of two or more components of MS in a large population base of elderly men and women, and to compare them with the corresponding values of the JIS ${ }^{3}$ recommendations for adults.

\section{METHOD}

The present analysis used baseline data from the Bambuí elderly cohort study, conducted in the city of the same name, which has around 15,000 inhabitants and is located in the state of Minas Gerais, Brazil. Among the 1,742 residents aged 60 and over, 1,606 participated in the baseline survey procedures. More details can be found in a previous publication ${ }^{8}$. The Bambuí elderly cohort study was approved by the Fiocruz Ethics Committee, Rio de Janeiro, in 1996.
Participants signed an Informed Consent Term for all the study procedures.

The JIS ${ }^{3}$ defines MS by the presence of at least three of the following five components: (1) waist circumference $\geq 90 \mathrm{~cm}$ for men and $\geq 80 \mathrm{~cm}$ for women; (2) triglycerides $>150 \mathrm{mg} / \mathrm{dL}$ for both genders; (3) HDL-cholesterol $<40 \mathrm{mg} / \mathrm{dL}$ for men and $<50 \mathrm{mg} / \mathrm{dL}$ for women; (4) glycemia $>100$ $\mathrm{mg} / \mathrm{dL}$ or history of medical diagnosis of diabetes and/or use of hypoglycemic agents; and (5) systolic pressure $>130 \mathrm{mmHg}$ and/or diastolic pressure $>85 \mathrm{mmHg}$ and/or use of antihypertensives. The outcome was defined by the presence of two or more of the components mentioned, excluding waist circumference.

Waist circumference measurement was performed in triplicate at the midpoint between the lower edge of the last rib and the iliac crest. The average of three measures was considered. The evaluators were trained by a nutritionist, and reliability analysis was performed for a sample of $10 \%$ of those evaluated. No significant differences were found among the evaluators'. Pressure levels were measured after 30 minutes or more of the last intake of caffeine or cigarette smoked. Three measurements were performed after five minutes of initial rest and then at two-minute intervals, and the mean of the second and third measurements were considered. Blood collection was performed after a recommended 12 hours of fasting. The dosages of glycemia, HDL cholesterol and triglycerides were determined by traditional enzymatic methods ${ }^{8}$. The use of medications was evaluated through a face-to-face interview, and the prescriptions and/or packaging of drugs consumed were requested.

Initially, the best cut-off point for waist circumference for the prediction of two or more other components of MS in the study population was based on the cut-off points proposed by Wang et al. ${ }^{6}$. Each waist circumference value between 75 $\mathrm{cm}$ and $95 \mathrm{~cm}$ was evaluated in a stratified analysis by gender. The best cut point was determined by the highest Youden Index (YI), $88 \mathrm{~cm}$ for men (YI=0.346) and $92 \mathrm{~cm}$ for women (YI=0.209). Next, the accuracy of the waist circumference cut-off point obtained in the analysis described was determined, 
as well as the cut-off points recommended by the $\mathrm{JIS}^{2}$. Accuracy was assessed using the area under the Receiver Operating Characteristic (AUROC) curve, sensitivity, specificity, and positive and negative predictive values.

\section{RESULTS}

Among the cohort baseline participants, there was complete information for all the study variables for 1,383 individuals included in this analysis. The mean age of participants was $68.9(+7.0)$ years, with a predominance of women $(60.9 \%)$. The overall prevalence of MS based on the JIS definition was $55.8 \%$. This prevalence was higher among women $(63.8 \%)$ than men $(43.4 \%)$. The cut-off points that best predicted two or more MS components in the study population were $88 \mathrm{~cm}$ and $92 \mathrm{~cm}$ for men and women, respectively.
Table 1 shows the results of the waist circumference accuracy analysis, using the cut-off point that presented the best prediction for MS in the present analysis and that recommended by the JIS. Among men, the AUROC was similar for the two cut-off points. The sensitivity and specificity of the first measurement of waist circumference were the same, as were the corresponding values for the cut-off point recommended by JIS. The positive and negative predictive values using each of these measures were similar. In contrast, the use of the two cut-off points among women produced different results, with the AUROC found to be higher using the first measurement. The sensitivity for the prediction of two or more components of MS, meanwhile, was higher using the second measurement. The corresponding values for specificity of the first measurement were higher than those of the second. The positive and negative predictive values were similar for each of the two cut-off points.

Table 1. Accuracy of waist circumference for the prediction of two or more of four components of metabolic syndrome (Baseline of the Bambuí Elderly Cohort Study).

\begin{tabular}{|c|c|c|c|c|c|c|}
\hline $\begin{array}{l}\text { Waist } \\
\text { circumference }\end{array}$ & $\begin{array}{l}\text { Prevalence of } \\
\text { two or more } \\
\text { components* }\end{array}$ & $\begin{array}{l}\text { AUROC } \\
(\mathrm{CI} 95 \%)\end{array}$ & Sensitivity & Specificity & $\begin{array}{l}\text { Positive } \\
\text { Predictive } \\
\text { Value }\end{array}$ & $\begin{array}{l}\text { Negative } \\
\text { Predictive } \\
\text { Value }\end{array}$ \\
\hline Men & 0.577 & & & & & \\
\hline$\geq 88 \mathrm{~cm}^{* *}$ & & $\begin{array}{l}0.673 \\
(0.633-0.713)\end{array}$ & 0.721 & 0.624 & 0.723 & 0.622 \\
\hline$\geq 90 \mathrm{~cm}^{* * *}$ & & $\begin{array}{l}0.672 \\
(0.632-0.712)\end{array}$ & 0.641 & 0.703 & 0.746 & 0.589 \\
\hline$P$ value & & 0.948 & & & & \\
\hline Women & 0.680 & & & & & \\
\hline$\geq 92 \mathrm{~cm}^{* *}$ & & $\begin{array}{l}0.605 \\
(0.569-0.639)\end{array}$ & 0.565 & 0.645 & 0.720 & 0.485 \\
\hline$\geq 80 \mathrm{~cm}^{* * *}$ & & $\begin{array}{l}0.560 \\
(0.533-0.588)\end{array}$ & 0.906 & 0.215 & 0.709 & 0.518 \\
\hline$P$ value & & 0.014 & & & & \\
\hline
\end{tabular}

*Two or more of the following components: Triglycerides $\geq 150 \mathrm{mg} / \mathrm{dL} ; \mathrm{HDL}$-cholesterol $\leq 40 \mathrm{mg} / \mathrm{dL}$ among men and $\leq 50 \mathrm{mg} / \mathrm{dL}$ among women; systolic blood pressure $\geq 135 \mathrm{~mm} / \mathrm{Hg}$ and/or diastolic blood pressure $\geq 85 \mathrm{~mm} / \mathrm{Hg}$; fasting blood sugar level $\geq 100 \mathrm{mg} / \mathrm{dL}$; ** Cut-off point that best discriminates two or more components in the study population; ${ }^{* * *}$ Cut-off point recommended by the Joint Interim Statement JIS; AUC = area under the ROC curve (receiver operating characteristic); AUROC $=$ area under the ROC curve; $p$ value $=\mathrm{Z}$ test for comparison between areas under the curve; sensitivity: proportion of increased waist circumference (positive) among those with two or more components (true positives); specificity: proportion of negatives among those who did not have two or more components (true negatives); positive predictive value: proportion of people with two or more components among individuals with increased waist circumference; negative predictive value: proportion of people who did not have two or more components among individuals with adequate waist circumference. 


\section{DISCUSSION}

The main results of this study were as follows: (1) the waist circumference cut-off point which best predicted two or more components of MS among the men in the study population was similar to that recommended by the JIS for the adult population (2) the best waist circumference cut-off point for women was higher than that recommended by the JIS.

Among men, the adoption of the cut-off point that best predicted the other components of MS in the study population and that recommended by the JIS resulted in similar sensitivity and specificity. The results differed among women, however, with higher sensitivity for the cut-off point recommended by the JIS than the measured cut-off point. In contrast, as expected, the specificities for the cut-off points were lower for the former measure than the latter.

Positive and negative predictive values were also used in this analysis. These are important measures from a public health perspective, since, in addition to sensitivity and specificity, they also consider the prevalence of the disease in the population. Our results found similar predictive values for both genders for both the cut-off point which best predicted the other components of MS in the study population and that recommended by the JIS.

The main measure used in this analysis to examine the accuracy of different waist circumference cut-off points for the prediction of two or more components of MS was the area under the ROC curve. This

\section{REFERENCES}

1. Bortoletto MSS, De Souza RKT, Cabrera MAS, González AD. Síndrome metabólica, componentes e fatores associados em adultos de 40 anos ou mais de um município da Região Sul do Brasil. Cad Saúde Coletiva [Internet]. 2016 [acesso em 15 jan. 2018];24(1):32-40. Disponível em: http://www. scielo.br/pdf/cadsc/v24n1/1414-462X-cadsc-1414462X201600010123.pdf

2. Chuang TJ, Huang CL, Lee CH, Hsieh CH, Hung YJ, Hung CF, et al. The Differences of metabolic syndrome in elderly subgroups: a special focus on young-old, old-old and oldest old. Arch Gerontol Geriatr [Internet]. 2016 [acesso em 11 jan. area represents the overall performance of the test, combining the sensitivity and specificity of the measure for the outcome. The better the test, the more the area under the curve approaches the value of 1 , while values equal to 0.50 represent an accuracy due to chance. Values of 0.90 can be interpreted as high, those from 0.7 to 0.89 as moderate and those

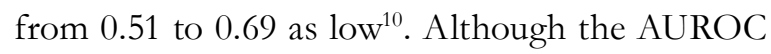
was higher than the cut-off point defined in this study among women, our results show low overall accuracy for all the waist circumference cut-off points analyzed.

The main advantage of this study is its large population base. Although all precautions were taken to ensure the standardization and quality of the measurements performed, there is always the possibility of regression to the mean, which may have attenuated the validity measures used in this analysis. In any case, however, this factor could not explain the low accuracy found. As the study was conducted in a single population, it is not known whether the results can be generalized to other elderly populations.

\section{CONCLUSION}

The overall validity of the use of waist circumference for the prediction of two or more components of Metabolic Syndrome was low for both genders, indicating that this measure does not adequately predict other components of this syndrome in the study population.
2018];65(1):92-7. Disponível em: https://www.ncbi. nlm.nih.gov/pubmed/27016645

3. Alberti KG, Eckel RH, Grundy SM, Zimmet PZ, Cleeman JI, Donato KA, et al. Harmonizing the metabolic syndrome: a joint interim statement of the International Diabetes Federation Task Force on Epidemiology and Prevention; National Heart, Lung, and Blood Institute; American Heart Association; World Heart Federation; International Atherosclerosis Society; and International Association for the Study of Obesity. Circulation [Internet]. 2009 [acesso em 09 nov. 2017];120(16):1640-5. Disponível em: http://circ. ahajournals.org/content/120/16/1640 
4. Liang H, Chen X, Chen Q, Wang Y, Wu X, Li Y, et al. The metabolic syndrome among postmenopausal women in rural canton: prevalence, associated factors, and the optimal obesity and atherogenic indices. PLoS One [Internet]. 2013 [acesso em 15 dez. 2017];8(9):1-8.Disponível em: https://www.ncbi.nlm. nih.gov/pubmed/24040183

5. Gharipour M, Sadeghi M, Dianatkhah M, Bidmeshgi S, Ahmadi A, Tahri M, et al. The cut-off values of anthropometric indices for identifying subjects at risk for metabolic syndrome in Iranian elderly men. J obes [Internet]. 2014 [acesso em 08 dez. 2017];2014:1-6. Disponível em: https://www. hindawi.com/journals/jobe/2014/907149/cta/

6. Zeng Q, He Y, Dong S, Zhao X, Chen Z, Song $Z$, et al. Optimal cut-off values of BMI, waist circumference and waist:height ratio for defining obesity in Chinese adults. Br J Nutr. [Internet]. 2014 [acesso em 12 dez. 2017];112(10):1735-44. Disponível em: https://www.ncbi.nlm.nih.gov/ pubmed/25300318.

Recebido: 29/03/2018

Revisado: $15 / 04 / 2018$

Aprovado: 20/04/2018
7. Wang F, Wu S, Song Y, Tang X, Marshall R, Liang M et al. Waist circumference, body mass index and waist to hip ratio for prediction of the metabolic syndrome in Chinese. Nutr Metab Cardiovasc Dis [Internet]. 2009 [acesso em 04 out. 2017];19(8):542-7. Disponível em: https://www.sciencedirect.com/science/article/ pii/S0939475308002275

8. Lima-Costa MF, Firmo JOA, Uchoa E. Cohort Profile: The Bambuí (Brazil) Cohort Study of Ageing. Int J Epidemiol. 2011;40(4):862-7.

9. Lopes ACS, Caiaffa WT, Sichieri R, Mingoti, SA, Lima-Costa MF. Estado Nutricional: antropometria, consumo alimentar e dosagens bioquímicas de adultos e idosos: Projeto Bambuí um estudo de base populacional. Rev Min Enferm [Internet]. 2008 [acesso em 28 jan. 2018];12(4):483-93 Disponível em: http://www.reme.org.br/artigo/detalhes/292

10. Fischer JE, Bachmann LM, Jaeschke, R. A Readers' guide to the interpretation of diagnostic test properties: clinical example of sepsis. Intensive Care Med [Internet]. 2003 [acesso em 31 jan. 2018];29:104351. Disponível em: https://www.ncbi.nlm.nih.gov/ pubmed/12734652 